\title{
Designing and Development of Solar Air Conditioner System for Automobiles
}

\author{
Ravinder Goyal ${ }^{1}$, Kanwar J.S Gill ${ }^{2}$, Kulvir Singh ${ }^{3}$, Harinder Singh ${ }^{4}$, Prince Rajpal ${ }^{4}$
}

\author{
1. (Head, Department of Automobile Engineering, Gulzar Group of Institutes,Ludhiana,PTU,India.) \\ 2. (Head, Department of Mechanical Engineering, Gulzar Group of Institutes,Ludhiana,PTU,India.) \\ 3. (Asst.Prof., Department of Automobile Engineering, Gulzar Group of Institutes,Ludhiana,PTU,India.) \\ 4. (Students, Department of Automobile Engineering, Gulzar Group of Institutes,Ludhiana,PTU,India.)
}

\begin{abstract}
Now-a-days, we are in high need for using natural resources like fuel, coal etc., and we have to face harsh consequences for the increasing demand. So, from this it is clear that present pace to consumption of energy, especially oil, cannot be sustained longer time in future. Again, this play negative role in global warming. Therefore, under these conditions it is much needed to make a new exploration of some other natural resource of energy and power. So one of this effective source is "Solar Energy".

This paper shows the work done in designing and fabrication of solar Air Condition system which is meant specially for creating green environment. We have used PV solar cell, this cell can directly change the solar energy into electric energy. Then we have used the battery for storage of collected solar energy. We have used single phase DC motor and this motor is move by battery power. This motor is transfer the power to compressor to move and start the next process. One of the promising method is absorption system. The absorption cycle is same in certain respects to the electrically driven vapor compression machines. A refrigeration cycle is operated with the condenser, expansion valve, and evaporator if low-pressure vapor from the evaporator can be transformed into high pressure vapor and delivered to the condenser. The vapor compression system uses a compressor for this task. The absorption system first absorbs the low pressure vapor in an appropriate absorbing liquid. Embodied in the absorption process is the conversion of vapor into liquid, and since the process is akin to condensation, heat must be rejected during the process. To elevate the pressure of the liquid with a pump is the next step, and releases of the vapor from the absorbing liquid by adding heat is the final step. Both cycles can be shown in same methods of transforming low-pressure vapor into high-pressure vapor in a refrigeration system.
\end{abstract}

Keywords - Condenser, Compressor, designed, fabricated.

\section{INTRODUCTION}

To save the precious environment one of the major steps taken is development of solar powered run vehicle which not only shall save us only but will save our coming off springs, which has been disturbed day to day by the high level increase in the pollution being emitted by all the vehicles having internal combustion engines. Not only limited to vehicles pollution is also emitted by industries.

While the solar vehicle is based on the concept of utilizing solar energy in to the mechanical energy, the design of this vehicle allows for fewer moving parts which lead to higher efficiency in terms of mileage and reliability. As we all are in a need for eco-friendly environment which is a basic necessity not only for us but for our coming next generations also. Hence by gaining a lot from the past polluted environment design and development of solar car was a mandatory step. In lieu of that solar vehicle was developed having many features like one can use as a passenger vehicle, as an load carrier also, even teenagers can also use it who are not having licence to run an Internal combustion engine powered vehicles. One can have its use in hospitals also where zero noise zones are there. To reduce the weight of the vehicle rectangular hollow pipes are considered.

\section{A. RESEARCH OBJECTIVE}

Sunlight is now-a-days considered to be a source of energy which is implemented in various day to day applications. Solar energy is being used to produce electricity through sunlight. With the help of this technology we aim to make solar energy powered air conditioning system. Our objective was to implement our idea on a 
car and afterwards with the help of this prototype we extended our future work on building an actual system powered by the solar energy which is both cost effective and of course environment friendly. We also intend to solve the problem of voltage fluctuation due to the fact of cloud, earth movement, sun movement etc.

\section{B. GLOBAL WARMING}

A worldwide temperature alteration is the expansion of Earth's normal surface temperature because of impact of nursery gasses, for example, carbon dioxide outflows from smoldering fossil energizes or from deforestation, which trap warm that would some way or another break from Earth. This is a sort of nursery impact. Among the environmental harms incited by a worldwide temperature alteration, the vanishing of some imperiled species is a worry since it destabilizes the common assets that nourish a few populaces.

There are likewise worries about the relocation of a few animal categories from warm oceans to beforehand colder northern oceans, where they can conceivably annihilate indigenous species and the economies that live off those species. This might be occurring in the Mediterranean Sea, where barracudas from the Red Sea have been watched. [1-2]

Common fiascos order our consideration more than environmental debacles as a result of the sufficiency of the harm they cause. An Earth-wide temperature boost is accepted to have impelled meteorological marvels, for example, "El Niño," which irritates the South-Pacific area and frequently causes tornadoes, immersions, and dryness.

The liquefying of the polar ice caps, another real after effect of a dangerous atmospheric devation, raises the ocean level and can bring about the perpetual immersion of beach front areas, and now and again of whole countries. The most critical nursery gas is really water vapor, not something created straight forwardly by mankind in noteworthy sums. Be that as it may, even slight increments in climatic levels of carbon dioxide $(\mathrm{CO} 2)$ can bring about a considerable increment in temperature.

Why would that be? There are two reasons: First, in spite of the fact that the centralizations of these gasses are not almost as substantial as that of oxygen and nitrogen (the principle constituents of the climate) neither oxygen nor nitrogen is nursery gasses. This is on account of neither has more than two atoms for every particle (i.e. their sub-atomic structures are $\mathrm{O}_{2}$ and $\mathrm{N}_{2}$, separately), thus they do not have the inside vibrational modes that particles with more than two molecules have. Both water and $\mathrm{CO}_{2}$, for instance, have these "inward vibrational modes", and these vibrational modes can assimilate and reradiate infrared radiation, which causes the nursery impact.

Also, $\mathrm{CO}_{2}$ has a tendency to stay in the climate for quite a while (time scales in the many years). Water vapor, then again, can without much of a stretch gather or dissipate, contingent upon neighborhood conditions. Water vapor levels along these lines have a tendency to change rapidly to the predominant conditions, such that the vitality streams from the Sun and re-radiation from the Earth accomplish an equalization. $\mathrm{CO}_{2}$ has a tendency to remain genuinely steady and in this way carry on as a controlling component, instead of a responding variable. More $\mathrm{CO}_{2}$ implies that the parity happens at higher temperatures and water vapor levels.

\section{ELECTRIC AIR CONDITIONER}

In Electric Air Conditioner It consist of electric motor which provides traction, chemical batteries, fuel cells, and capacitors, or flywheels as sources of corresponding energy [3-4]. The electric Air Conditioner has many advantages. Over the Solar powered Air Conditioners, such as high efficiency, smooth and quiet operation. The fundamental and operational principles in Electric Air Conditioner and Solar Air Conditioner almost similar. There are, however, some differences between Electric Air Conditioner and Solar Air Conditioner, such as the use of Solar panel vs. batteries. 


\section{DESIGN OF SOLAR AIR CONDITIONER}

The fundamentals of air conditioner design involve the basic principles of

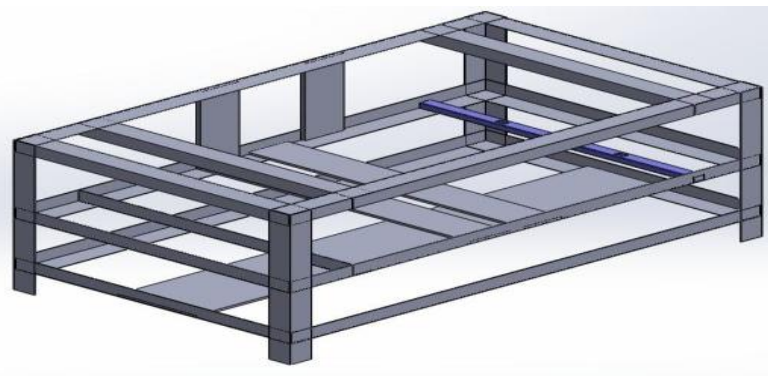
physics.

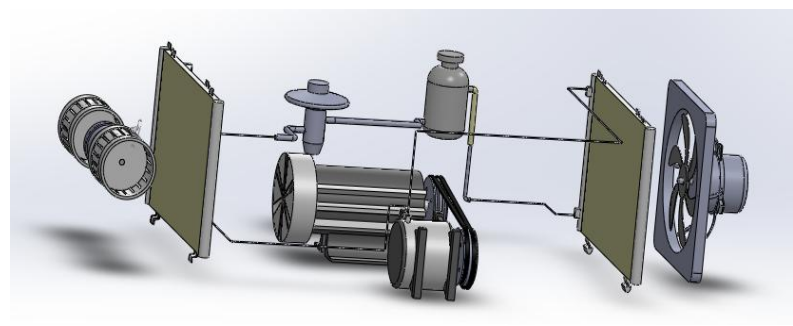

FIRST STEP: First of all a frame is made on which every part is mounted. We have used the "L" type angles and joined them with nut bolts to create a frame of out project on which mountings are to be held. And this angle size is 1.50 " by 1.50 ". Full dimension of Frame is 60 " $\mathrm{x}$ $35 " \times 35 "$.

Fig:-2 Frame of Solar Air Conditioner

SECOND STEP: A.C system is mounted on the frame. A.C components are compressor, condenser, purifier, expansion valve, evaporator, cooling fan, Ac blower etc.

\section{Fig:-3 Assembly of Solar Air Conditioner}

THIRD STEP: Solar system is mounted on the frame. Solar

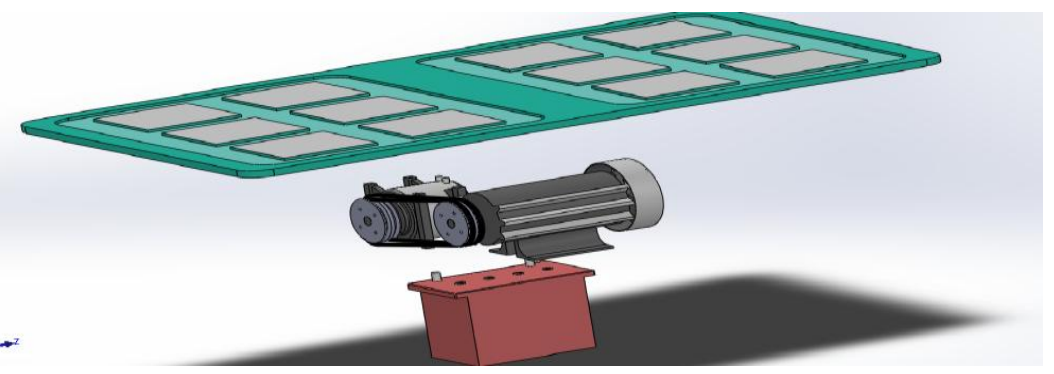
cell, Invertor, Battery, Motor. We have used P.V cell (Photovoltaic cell). This cell directly converts the solar energy

to electronic energy. We connected the battery to get charge by solar energy. Then the motor is connected to the battery which let the motor rotates. The motor used here is the 1H.P DC motor.

\section{Fig:-4 Solar A/c Panel and Motor}

Final StEP: Adjoining of all systems on the frame. All things are mounted on the Frame. A.C system, Solar system, Battery.

Fig:-5 Assembled Solar A/C 


\section{HOW IT WORKS}

PROCESS-1:- At high pressure and high temperature, refrigerant is in the liquid state. It flows to

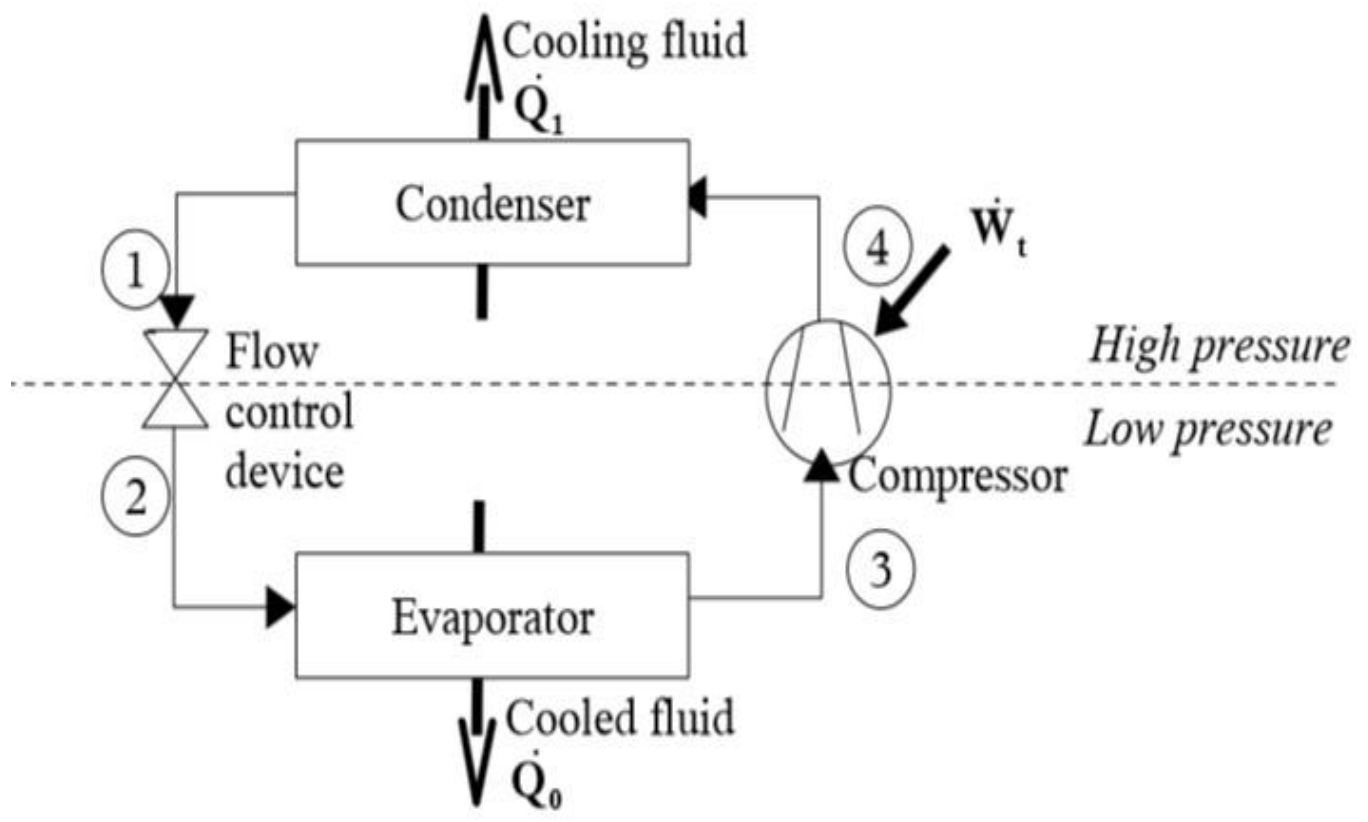

though a restriction, known as flow control device. The pressure of refrigerant decreases through the restriction. At a very low pressure that a small portion of the refrigerant vaporize into a gas. But in order to vaporize, it requires heat, thus cooling the mixture and results in a low temperature.

\section{Fig:-5 Air Conditioner working}

PROCESS-2:- The refrigerant passes inside a heat exchanger known as the evaporator. This heat exchanger has two circuits. One for the refrigerant circulates, other for the fluid to be cooled (mostly air or water) flows. The fluid, which to be cooled is at a higher temperature than the refrigerant; therefore heat is transferred from it to the refrigerant, which produces the desired cooling effect. Because of the heat it receives the refrigerant boils in the evaporator. By the time it gets vaporized.

PROCESS-3:- At a low temperature and low pressure by leaving the evaporator the refrigerant is a gas. In order to be able to use it again to achieve refrigerating effect continuously, it must be brought back to the conditions at liquid at a high pressure. The first step in this process is to increase the pressure of the refrigerant gas by using a compressor. Compressing the gas also results in increasing its temperature.

PROCESS-4:- The refrigerant leaves the compressor as a gas at high temperature and weight. Keeping in mind the end goal to change it to a fluid, heat must be expelled from it. This is expert in a warmth exchanger called the condenser. The refrigerant courses through one circuit in the 
condenser. In the other Circuit, a cooling liquid streams (air or water) at a temperature lower than the refrigerant. Warm in this way exchanges from the refrigerant to the cooling liquid, and therefore, the refrigerant gathers to a fluid. A compressor can be driven mechanically from an outside source by an uncovered shaft (with a seal to counteract spillage), or be worked as a solitary unit with an electric driving engine and the real compressor fixed in a packaging. The previous is called an open compressor and the later a hermetic compressor.

\section{TECHINICAL DETAILS OF SOLAR PANEL}

- Typical module efficiencies $\sim 12 \%$

- Screen printed multi-crystalline solar cells

- Efficiency range is 6-30\%

- $6 \%$ for amorphous silicon-based PV cells

- $20 \%$ for best commercial cells

- $30 \%$ for multi-junction research cells

- Typical power of $120 \mathrm{~W} / \mathrm{m}^{2}$

- Mar/Sep equinox in full sun at equator

- $\sim 1 \mathrm{~kW} / \mathrm{m}^{2}$ reaches the ground (sunny day)

- $\sim 20 \%$ efficiency $\Rightarrow 200 \mathrm{~W} / \mathrm{m}^{2}$ electricity

- Daylight \& weather in northern latitudes

- $100 \mathrm{~W} / \mathrm{m}^{2}$ in winter; $250 \mathrm{~W} / \mathrm{m}^{2}$ in summer

\begin{tabular}{|c|c|}
\hline Batteries 15 plate & 02 \\
\hline Weight of batteries & $46 \mathrm{Kg}$. \\
\hline Battery capacity & $100 \mathrm{~A}$ \\
\hline Battery pack voltage & 24 Volts \\
\hline
\end{tabular}

- Or 20 to $50 \mathrm{~W} / \mathrm{m}^{2}$ from solar cells

\section{CONCLUSION}

There are a few sorts of sun powered strategies that are presently accessible. Be that as it may, each of them depends on very distinctive ideas and science and each has its one of a kind points of interest. Examination and correlation between various advances will help us to embrace the most effective and useful innovation given a particular arrangement of conditions.

The car business is continually advancing and designing new advances. Amplifying productivity and minimizing the destructive impacts of vehicles on nature and society are the essential objectives of car architects. In any case, the sun oriented ventilation system for vehicle is another innovation being executed to achieve these objectives.

Accentuation has been put on photovoltaic sun oriented boards (PV) and concentrated sunlight based force (CSP), since they are the two most generally conveyed advancements and are relied upon to have quick development in both the short-and long-terms. We have assessed and thought about their component, structure, proficiency, alongside other specialized subtle elements.

The impacts and effects that sunlight based aeration and cooling system for vehicle have on nature and society from a designing perspective were talked about, and the data exhibited here served to be instructive. All parts of an EV were examined, for example, how sun based aeration and cooling system for vehicle work and what they are, the complexities and the expense of owning and sun powered ventilation system for vehicle and how it impacts the economy.

1. This system may be used as a passenger vehicle along with loader vehicle.

2. This system may be used in case if a fuel crisis as it is fitted with recyclable and rechargeable batteries.

3. It is an eco-friendly system as no pollution is being omitted. 
4. Almost $100 \%$ of these batteries can be recycled, which keeps old batteries from becoming a disposal problem.

5. It is easy to impalement.

6. It uses the energy as solar energy to charge the batteries.

\section{ACKNOWLEDGEMENT}

We are highly thankful to the Management of Gulzar Group of Institutes, Ludhiana for providing us Research and Development facility in this Institute due to which it has been possible to design and develop this very project. We are highly thankful, especially to our Executive Director, Er. Gurkirat Singh Ji for helping us by all means and we are also thankful to our campus Director Prof. Dr. Vijay Athawale for encouraging us in every field.
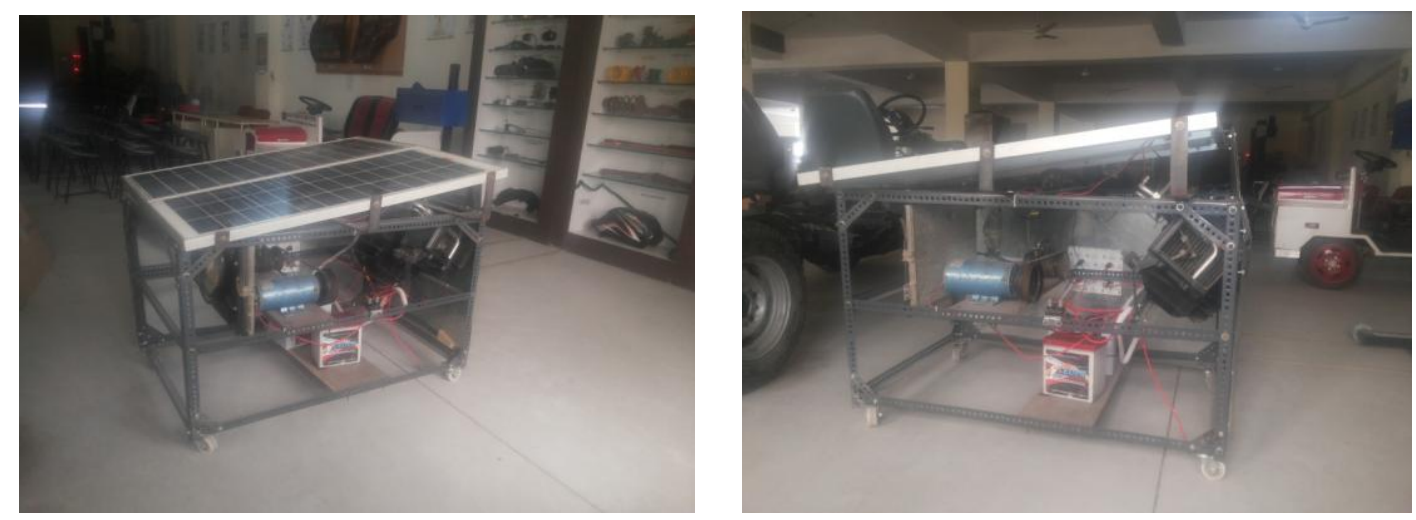

\section{REFERENCES}

[1] C.C. Chan and K.T. Chau, Modern Electric Vehicle Technology, Oxford University Press, New York, 2001.

[2] K.M. Rahman and M. Ehsani, Performance analysis of electric motor drives for electric and hybrid electric vehicle application, IEEE Power Electronic in Transportation, 29-26, 1996.

[3] Y. Gao, H. Maghbelli, M. Ehsani, et al., Investigation of proper motor drive characteristics for military vehicle propulsion, Society of Automotive Engineers (SAE) Journal, Paper No. 2003-012296, Warrendale, PA, 2003.

[4] Z. Rahman. M. Ehsani, and K. Butler, An investigation of electric motor drive characteristics for EV and HEV propulsion systems, Society of Automotive Engineers (SAE) Journal, Paper No. 2000-01-3062, Warrendale, PA, 2003. 